\title{
FISH DIET IN THE DANUBE DELTA POPULATION - HEALTH BENEFITS IN SULINA'S PATIENTS
}

\author{
Georgiana Ene ${ }^{1}$, Cristian Lucian Petcu², Magda-loana Nenciu³ ${ }^{3}$ Natalia Roșoiu 4,5 \\ ${ }_{1}$ "Ovidius" University, Doctoral School of Applied Sciences, Constanta, Romania, \\ e-mail: enegeorgiana.biologie@yahoo.com , 1987 \\ 2 "Ovidius" University, Faculty of Dental Medicine, Department of Biophysics, \\ Constanta, Romania, e-mail: crilucpet@yahoo.co \\ ${ }^{3}$ National Institute for Marine Research and Development Grigore Antipa", 300 \\ Mamaia Blvd., RO-900581, Constanta, Romania, e-mail: \\ magdalena.nenciu@gmail.com \\ 4"Ovidius" University, Faculty of Medicine, Department of Biochemistry, Constanta, \\ Romania \\ ${ }^{5}$ Academy of Romanian Scientists, Bucharest, Romania, e-mail: \\ natalia rosoiu@yahoo.com
}

\begin{abstract}
According to literature data, the normal values of biochemical parameters in blood vary by sex, age, geographical region and type of diet. The aim of this study was to analyze the benefits of a fish-based diet among the population of Sulina Town, in the Danube Delta. The batch of patients underwent a set of biochemical tests in the RoutineMed Laboratory of Sulina. The novelty of the research is represented by the geographic area covered, as the Danube Delta had no medical analysis laboratory until 2010, when RoutineMed Laboratory was opened in Sulina. Blood samples were collected from 260 patients (of 3663 residents) for the evaluation of the serum markers and amino acid metabolism: creatinine, urea, uric acid. Both women and men were involved in the research and patients were grouped into age ranges: 20-40 years, 40-60 years, > 60 years. The study included 260 patients, of which 90 men (34.6\%) and 170 women $(65.4 \%)$, who declared they eat fish or fish-based products at least once a week. The values obtained were statistically analyzed using the SPSS v. 20 software and then compared to the ranges considered normal for these parameters. The results obtained showed that patients with a fish-based diet seem to be healthier than those with a diet in which fish meat is scarce, as their blood biochemical parameters values are closer to normal, which leads to the conclusion that including fish and fish products in people's regular diet is beneficial.
\end{abstract}

Keywords: creatinine, Danube Delta, fish diet, public health, urea, uric acid

\section{Introduction}

The aim of this study was to analyse the benefits of fish diet in the Danube Delta, Sulina's population. This study covers a part of the routine analyses performed on a selected group of patients presumed clinically healthy. Fish represents a major source of food for local inhabitants. Fish is an important source of protein with high biological value, containing all essential aminoacids. Urea nitrogen is the main final product of amino acid metabolism coming from the protein split in the stomach and intestine [1]. Blood and urine urea varies directly proportional to the protein diet [2]. 
Recommendations for determination of serum urea are: a hypoproteic diet with a high content of carbohydrates can cause decreases in serum urea, recent ingestion of a rich protein meal can cause values "borderline" increased level of serum urea. Increased protein intake ( $>200 \mathrm{~g} /$ day), especially if associated with reduced fluid intake, profuse sweating and polyuria induced by alcohol may increase serum urea up to $80 \mathrm{mg} / \mathrm{dL}$ [3]. Creatinine is the most fixed constituent of blood nitrogen, unaffected by most foods, exercise, circadian rhythm or other biological constants and is correlated with muscle metabolism. Reducing protein intake decreases the level of creatinine in correlation with the absence of amino acids arginine and glycine, creatine precursors [4,5]. A diet containing excessive meat can cause increases in serum creatinine (15-30\% of creatinine excreted daily result from food) [6]. Uric acid results from nucleic acids degradation, representing the final product of purine metabolism. Uric acid, urea and creatinine are synthesized in the liver then transported to the kidneys where it is filtered and excreted at a rate of about $70 \%$ [7].

Increase serum uric acid results when in the diet are introduced high molecular weight proteins, nucleoprotein in excess, alcohol, emotional stress, intense physical exercise, fasting, obesity. [8,9].

\section{Materials and Methods}

The novelty of the research is represented by analyzed geographic area. The Danube Delta had no medical analysis laboratory until 2010, when the RoutineMed Sulina laboratory was opened. Patients were subjected to a set of biochemical tests in the RoutineMed Sulina laboratory. They all declared they eat fish or fish-based products at least once a week. Blood samples were collected from 260 patients (of 3663 residents) for the evaluation of the serum markers and amino acid metabolism: creatinine, urea, uric acid. Both women and men were involved in the research and patients were grouped into age ranges: $20-40$ years, $40-60$ years, $>60$ years. Blood was collected and analyzed during September 2013 - august 2016. For serum biochemistry were used the following measuring instruments: Rotofix 32 A centrifuges, SAPPHIRE 350 automatic biochemistry unit and Audit Diagnostics reagents [10]. The experimental data were processed using IBM SPSS Statistics 20.

\section{Results and Discussion}

The study included 260 patients, 90 males (34,6 \%) and 170 females (65,4\%) (Fig.1); the distribution by age groups is: 91 are in the age range (20-40) years (35\%), 102 are in the age range (40-60) years (39.2\%) and 67 are in the age range (60 -..) years $(25,8 \%)$ ( Fig.2).

The mean of urea in the two groups of patients with a reference value $L_{\text {sup }}=50 \mathrm{mg} / \mathrm{dL}$ indicates that the results for both women and men are within normal limits; for the group of male patients the mean is- $\mathrm{MM}_{\mathrm{M}}=37.48 \mathrm{mg} / \mathrm{dL}$ and for the group of female patients the mean is $-M_{F}=32.22 \mathrm{mg} / \mathrm{dL}$ ( Fig.3).

When the mean of creatinine in the two groups of patients are compared with a reference value $L_{\text {sup }}=1,2 \mathrm{mg} / \mathrm{dL}$ for female and $L_{\text {sup }}=1,4 \mathrm{mg} / \mathrm{dL}$ for male : for the group of female patients the mean is $-M_{F}=0.84 \mathrm{mg} / \mathrm{dL}$ and for the group of male patients the mean is $-\mathrm{MM}_{\mathrm{M}}=0.92 \mathrm{mg} / \mathrm{dL}$ also indicates that the results for both women and men are within normal limits ( Fig.4).

Comparing the mean of uric acid in both groups of patients with a reference value Lsup $=5.7 \mathrm{mg} / \mathrm{dL}$ for female and $\mathrm{Lsup}_{=}=7 \mathrm{mg} / \mathrm{dLfor}$ male: for the group of female patients the 
mean is $-M_{F}=3.82 \mathrm{mg} / \mathrm{dL}$ and for the group of male patients the mean is $-\mathrm{MM}_{\mathrm{M}}=4.22$ mg/dL; ( Fig.5).

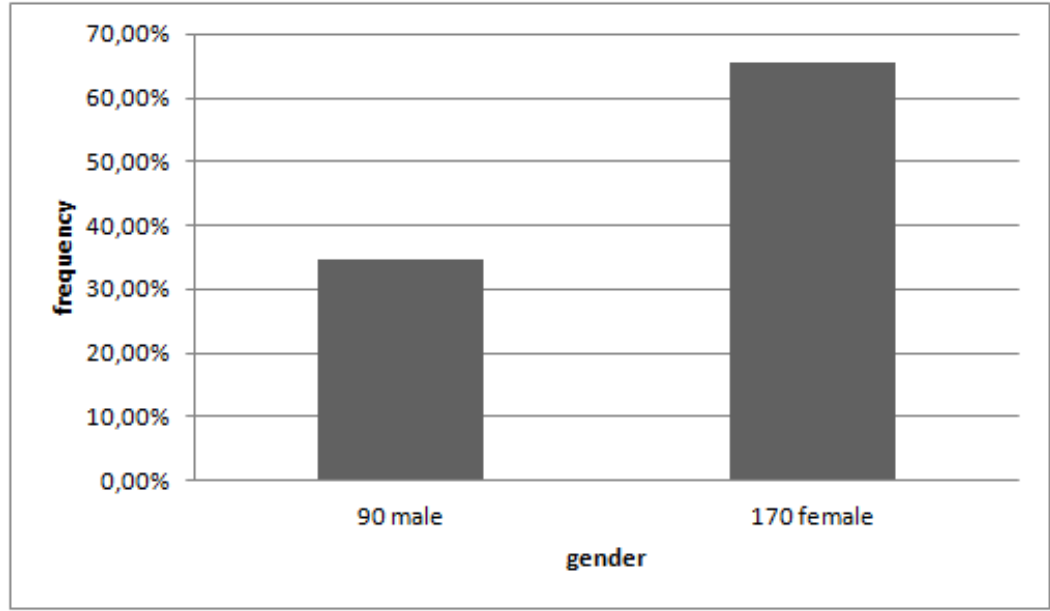

Figure 1. Patient distribution by gender

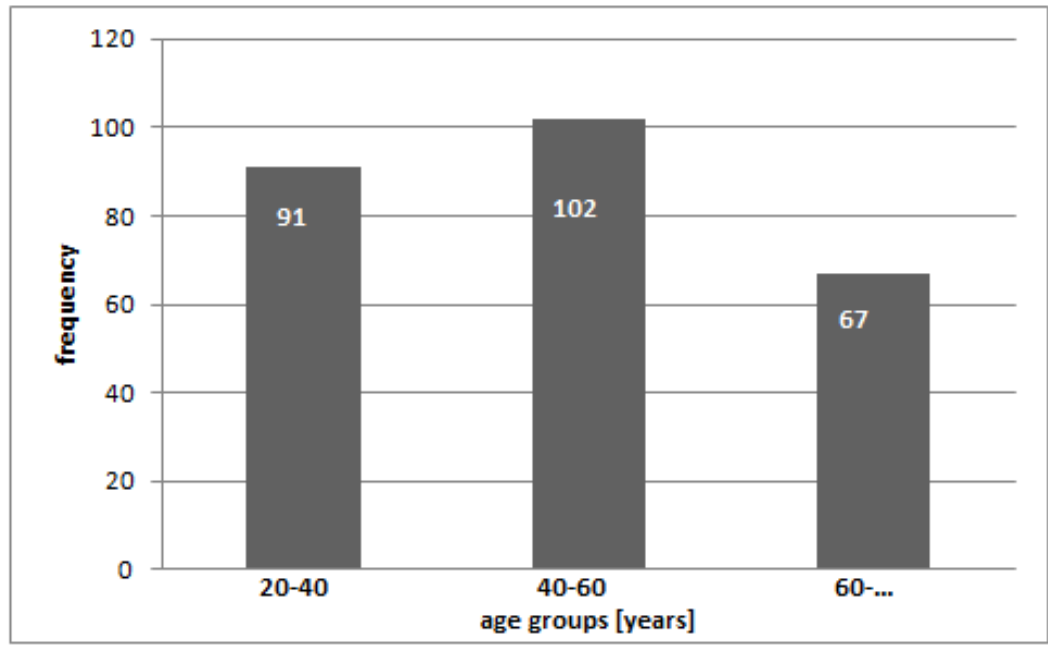

Figure 2. Patient distribution by age groups.

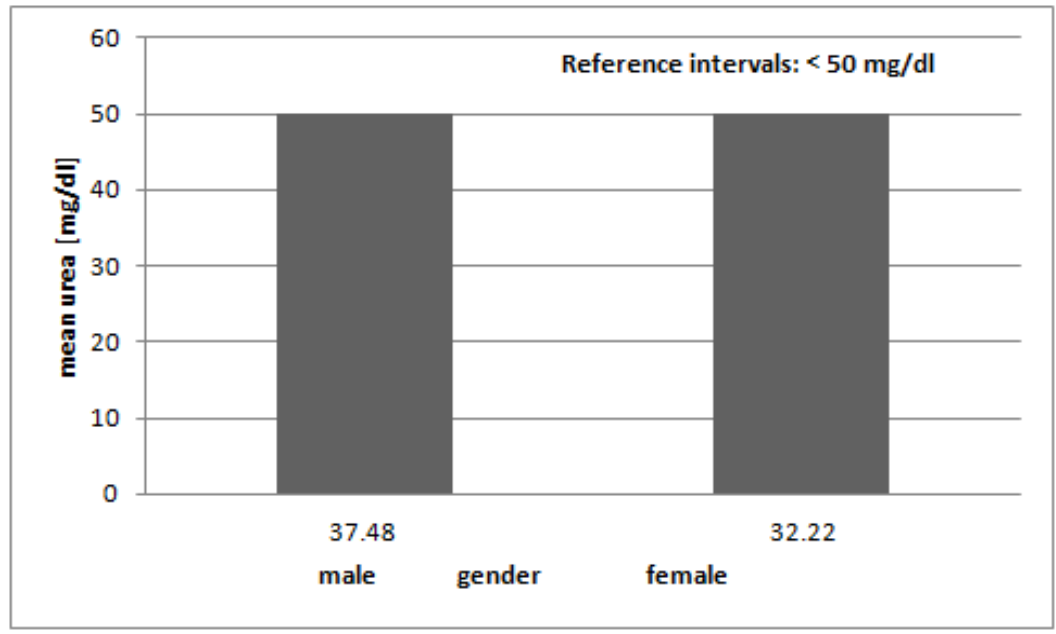

Figure 3. The average value of urea in males and females 


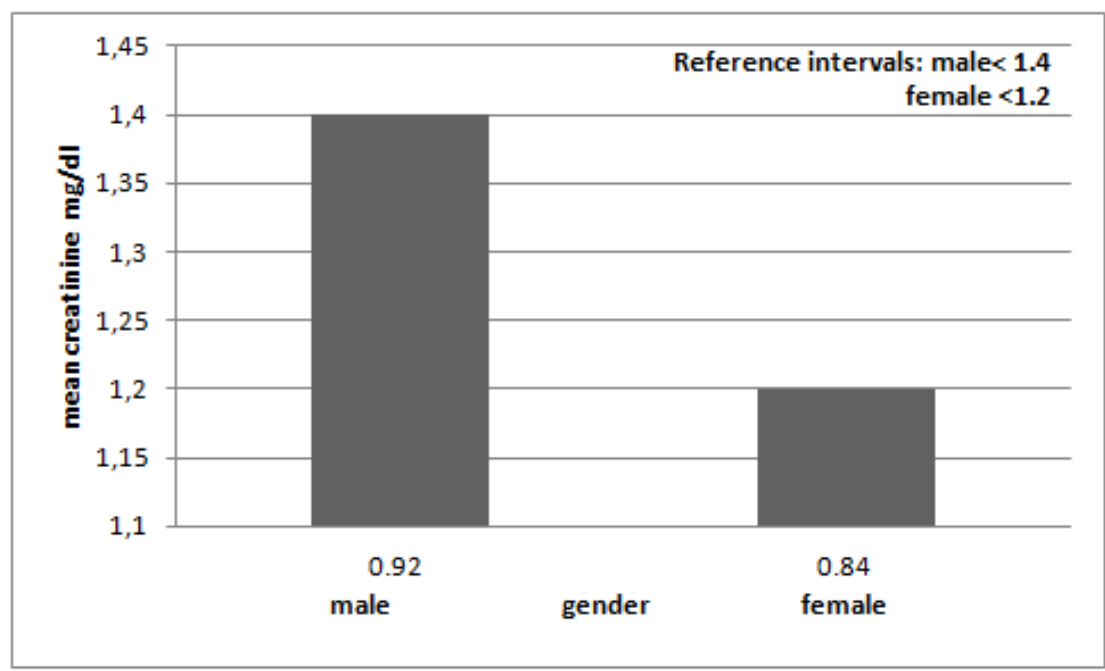

Figure 4. The average value of creatinine in males and females

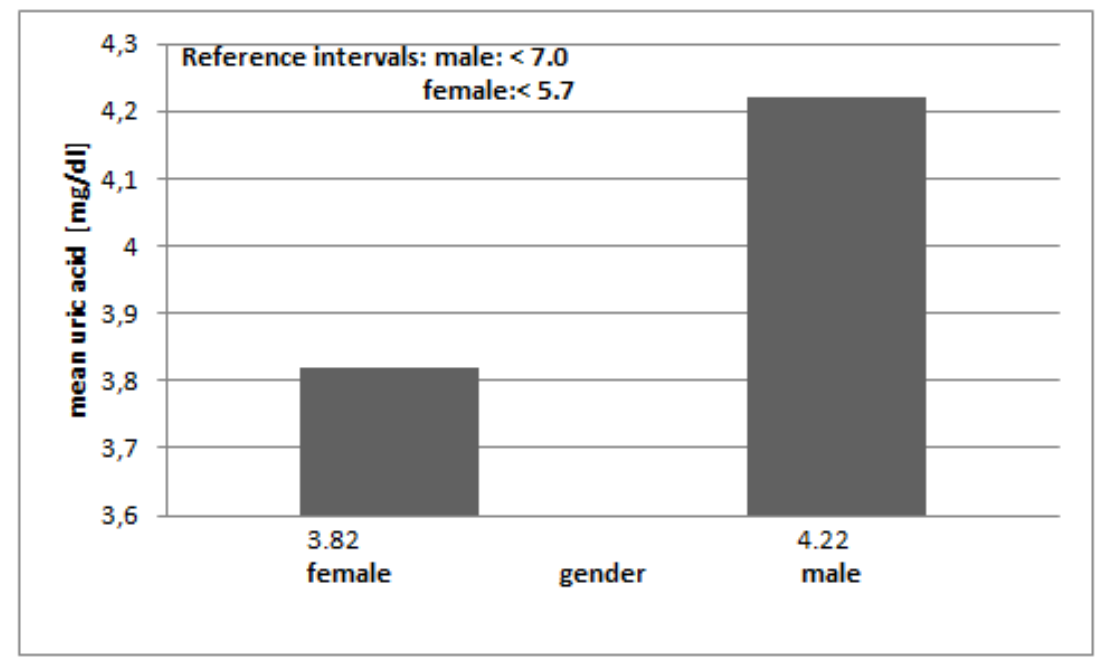

Figure 5. The average value of acid uric in males and females

\section{Discussion}

Serum urea value in both women and men indicate a normal glomerular function. A disturbance of renal function reduces the excretion of creatinine, leading to increased serum creatinine. Thus, concentrations of creatinine provides an approximation of the glomerular filtration rate. The main utility of determining serum creatinine is diagnosing kidney failure. Serum creatinine is a more specific and sensitive indicator of renal function than urea. However, chronic kidney disease is so useful to determine serum creatinine and urea. Hypouricemia and hyperuricemia are not the disease itself. While hyperuricemia is a risk factor for metabolic and may underlie the disease, may indicate a pathological condition hypouricemia unnoticed. Can register uric acid variations from day to day or from season to season to the same person.

\section{Conclusions}

The results obtained in the 260 patients from Sulina who declared they eat fish products at least once a week confirm the literature data and prove that people who consume fish regularly tend to be healthier. 
The results obtained so far indicates that fish and fish products really helps us maintain the normal level of total lipids and the liver metabolism [11]. Comparative hepatic evaluation and the lipid profile in Danube Delta patients with fish-based diets indicates health benefits.

Serum glucose levels and total protein profile in Danube Delta patients leads to the conclusion that including fish and fish products in people's regular diet is beneficial in preventing protein and carbohydrate metabolism disorders and preserving the overall health.

Including fish and fish products in people's regular diet is beneficial in preventing and screening osteoporosis in patients over 50 years, evaluation of biologically active fraction of calcium in pregnant women, detection of certain metabolic disorders of kidneys and hemoglobin is useful for detection and monitoring of anemia and polycythemia.

\section{Acknowledgements}

This research was completed within the $\mathrm{PhD}$ research program of the Doctoral Scho

\section{References}

[1] Lothar Thomas. Kidney and urinary tract.(1998) In Clinical Laboratory Diagnostics-Use and Assessment of Clinical laboratory Results. TH-Books Verlagsgesellschaft $\mathrm{mbH}$, Frankfurt /Main, Germany, 1 Ed., 374-377.

[2] Jacques Wallach. (2001) Analizele de sange. In Interpretarea testelor de diagnostic. Editura Stiintelor Medicale, Romania, 7 Ed., 110-111.

[3] Frances Fischbach.( 2009) Chemistry studies. In A Manual of Laboratory and Diagnostic Tests. Lippincott Williams \& Wilkins, USA, 8 Ed., , 369-370.

[4] Jacques Wallach.( 2001) Analizele de sange. In Interpretarea testelor de diagnostic. Editura Stiintelor Medicale, Romania, 7 Ed., 68-69.

[5] Lothar Thomas. (1998) Kidney and urinary tract. In Clinical Laboratory Diagnostics-Use and Assessment of Clinical laboratory Results. TH-Books Verlagsgesellschaft $\mathrm{mbH}$, Frankfurt /Main, Germany, 1 Ed.,366-370, 375.

[6] Frances Fischbach.(2009) Chemistry studies. In A Manual of Laboratory and Diagnostic Tests. Lippincott Williams \& Wilkins, USA, 7 Ed.,; 375-377.

[7] Frances Fischbach. (2009) Chemistry Studies. In A Manual of Laboratory and Diagnostic Tests. Lippincott Williams \& Wilkins, USA, 8 ed., 378-379.

[8] Lothar Thomas. (1998,) Uric acid. In Clinical Laboratory Diagnostics-Use and Assessment of Clinical Laboratory Results. TH-Books Verlagsgesellschaft $\mathrm{mbH}$, Frankfurt /Main, Germany,1 ed. 208-214.

[9] Jacques Wallach. (2001) Analizele de sange. In Interpretarea testelor de diagnostic. Editura Stiintelor Medicale, Romania, 7 ed.;49-51.

[10] RoutineMed(.2013,2014,2015) Biochemistry specific procedures;

[11] Georgiana Ene ${ }^{1}$, Lucian Petcu ${ }^{2}$, Natalia Roșoiu ${ }^{3,4}$ (2016) THE HEPATIC EVALUATION AND THE LIPID PROFILE IN DANUBE DELTA PATIENTS, Archives of the Balkan Medical Union, vol.2/2016 pg162-170 